ISSN 1518-3483

Licenciado sob uma Licença Creative Commons

\title{
Profissionalidade e formação docente: representações sociais de professores
}

\author{
Professionalism and teacher education: \\ social representations of teachers
}

\author{
Rejane Dias da Silva ${ }^{[a]}$, Adelaide Alves Dias $^{[b]}$, Sonia Pimenta de Araujo ${ }^{[b]^{*}}$ \\ [a] Universidade Federal de Pernambuco (UFPE), Recife, PE, Brasil \\ [b] Universidade Federal da Paraíba (UFPB), João Pessoa, PB, Brasil
}

\section{Resumo}

Este estudo analisa a representação social sobre a formação docente de professores da rede pública estadual de Pernambuco. Partimos do pressuposto que as Representações Sociais podem contribuir para desencadear práticas educativas e possibilitar o acesso ao seu conhecimento. Foram aplicados questionários de associação livre e associação dirigida a 80 professores de 20 escolas de ensinos fundamental e médio. Identificamos o campo semântico das representações sociais dos professores e os elementos que constituíam o núcleo central. Os resultados revelaram que as representações sobre a formação circulam em torno das categorias pedagógica, acadêmica e profissional. A categoria profissional foi

* RDS: Doutora em Educação, e-mail:rejanediasilva@hotmail.com

AAD: Doutora em Educação, e-mail: adelaide.ufpb@gmail.com

SPA: Doutora em Educação, e-mail: sopimenta1@gmail.com 
insignificante no campo das representações dos sujeitos investigados. O núcleo central dessas representações se organiza em torno da dimensão acadêmica. As representações da formação são ancoradas na categoria acadêmica indicando a forte influência da formação inicial em cursos de licenciatura, apesar de terem sido encontrados indícios de mudanças consubstanciadas na ênfase na categoria pedagógica encontrada nas representações dos professores.

Palavras-chave: Profissionalidade Docente. Representações Sociais. Prática Docente.

\section{Abstract}

This study examines the social representation of teacher training of teachers in public schools in Pernambuco State. We assume that the social representations can contribute to trigger educational practices and provide access to their knowledge. Questionnaires were used to free association and association led to 80 teachers from 20 schools in primary and secondary education. We identify the semantic field of social representations of teachers and the elements that constitute the core. The results revealed that the representations about the formation circulate around the categories educational, academic and professional. The category was insignificant in the field of representations of the subjects investigated. The core of these representations is organized around the academic dimension. The representations of the training are anchored in academic category indicating the strong influence of initial training in undergraduate programs, although they were found substantiated evidence of changes in emphasis in the teaching category found in the representations of teachers.

Keywords: Teacher Professionalism. Social Representations. Teaching Practice.

\section{Introdução}

As produções desenvolvidas na área educacional vêm fomentando a discussão da formação de professores e compartilhando a crença de que a base de conhecimento - entendida aqui como um corpo de 
compreensões, conhecimentos, habilidades e disposições necessárias a atuação de um professor em dada situação de ensino (SHULMAN, 1987) - permitiria estruturar a educação do professor e instruiria diretamente as práticas de formação. Nesse sentido, desenvolveram-se pesquisas com a intenção de melhorar a formação docente, iniciar um processo de profissionalização favorável à legitimidade da profissão e assim, transpor a concepção de docência ligada ao fazer vocacionado.

Então, iniciaram-se, na década de 1980, nos Estados Unidos e no Canadá, estudos acerca dos saberes docentes. Shulman (1986), Gauthier (1998), Tardif (2002) basearam seus estudos na premissa de que existe uma "base de conhecimento" para o ensino. Investigaram e sistematizaram esses saberes, buscando compreender a genealogia da atividade docente e convalidar um corpus de saberes mobilizados pelo professor.

No cenário nacional, Pimenta (2000, p. 17) ressalta a importância "de ressignificar os processos formativos a partir da reconsideração dos saberes necessários à docência, colocando a prática pedagógica e docente escolar como objeto de análise”. Muitos estudos (CUNHA, 1994; GATTI, 1997; LIBÂNEO, 1998; BRZEZINSKI, 1996) já apontaram o perigo do esvaziamento e aligeiramento que ocorrem nos cursos de licenciatura, a precariedade da formação inicial de professores, dentre outras mazelas. Porém o elemento imprescindível para o ensino - o professor — , segundo as discussões da área educacional, não vem recebendo formação adequada.

No Brasil, o processo de formação acadêmica do professor também tem sido um dos principais temas das pesquisas realizadas, mas relacionadas à formação e ao desenvolvimento profissional. De acordo com Ferreira (2003), só a partir dos últimos anos da década de 1990, iniciou-se no país a transformação do paradigma de pesquisa, ou seja, o pensamento do professor lentamente vai tomando espaço no âmbito da pesquisa sobre a sua formação.

Apesar da mudança do discurso, percebemos, nos processos de formação de professores, a continuidade de prática retrógrada e centrada no modelo tradicional, com a predominância da dicotomia entre teoria e 
prática. Na realidade, ainda sabemos muito pouco sobre como transformar os discursos em práticas efetivas.

Entretanto, quando olhamos o que vem sendo dito e publicado e a realidade das salas de aulas, podemos inferir que a mudança percebida acontece apenas no âmbito do discurso. Hoje quase todos falam do professor como profissional reflexivo, investigador de sua prática, produtor de saberes, elemento-chave das inovações curriculares na escola e principal responsável por seu desenvolvimento profissional, mas ainda há pouca clareza e concordância sobre o significado desses termos.

No caso específico deste estudo, nossa preocupação maior foi analisar a dimensão formativa dos professores que já atuam na educação básica, a fim de compreendermos como esses sujeitos representam a formação. Para isso, entendemos como necessário um enfoque que envolvesse outras teorias, para tentar explicá-la e analisá-la. Assim, elegemos, em nosso estudo, como objeto de pesquisa a representação social da formação dos professores da rede pública estadual de Pernambuco.

Utilizamos como aporte teórico a Teoria das Representações Sociais desenvolvida por Moscovici (1978) e demais autores da área, como Denise Jodelet (1989), Jean Claude Abric (1994) e outros, porque as representações sociais podem contribuir no desencadear das práticas educativas e possibilitar o acesso ao seu conhecimento.

A partir do exposto objetivamos, nesse estudo, compreender o processo da formação inicial dos professores da rede pública estadual, a partir da análise das representações sociais sobre a formação. Para tal, tomamos, como referências de análise, o processo de formação inicial do professor e a Teoria das Representações Sociais como aporte teórico metodológico. Tal fundamento teórico nos serviu como suporte, por compreendermos que o sujeito é construtivo e não predeterminado, ou seja, elabora, reelabora e altera os significados das coisas com as quais interage no ambiente social.

Este trabalho encontra-se estruturado da seguinte forma: primeiramente será apresentado referencial teórico; o processo de formação docente e a Teoria das Representações Sociais enfatizando os estudos 
desenvolvidos nessas áreas, a segunda parte aborda a descrição da metodologia, coleta e análise dos dados e apresentação e discussão dos resultados, por fim as considerações finais.

\section{O processo de formação docente e a Teoria das Representações Sociais}

Desde a criação das licenciaturas no Brasil, nas antigas faculdades de Filosofia, nos anos 1930, até os dias atuais, a formação de professores vem revelando desencontros e dilemas. Os problemas mais recorrentes são: dicotomia entre disciplinas específicas e disciplinas pedagógicas e entre bacharelado e licenciatura; desarticulação entre formação acadêmica e realidade prática.

Essas dicotomias e desarticulações tornaram-se objeto de estudo e discussão, sobretudo, a partir da década de 1980, quando se iniciou o movimento de reorganização da sociedade civil brasileira, depois de longo período de ditadura militar. Desde então, os problemas vivenciados pelas licenciaturas vêm sendo amplamente divulgados na literatura disponível, nos debates promovidos por entidades e em eventos, como os fóruns das licenciaturas promovidos pelas universidades.

Segundo Alves (1998), a formação do profissional não se dá, com exclusividade, em cursos de formação, e sim em múltiplas esferas, e os conhecimentos teóricos, prático-políticos, epistemológicos, pedagógicos, curriculares, didáticos e outros necessários ao exercício docente são tecidos em redes. Nessa perspectiva, o estudo das representações sociais acerca da formação docente possibilita aproximação do objeto definido, considerando-o no dinamismo que o gera. As representações sociais, de acordo com os autores da área, constituem um saber: o do senso comum, o saber prático, que orienta a conduta dos indivíduos e sua comunicação. Segundo Alloufa e Madeira (1990), o senso comum seria a síntese construída na relação sujeito-objeto, num tempo e num espaço. Assim, para se constituírem como um saber, as representações não podem existir 
isoladamente; supõem a articulação na lógica por meio da qual o sujeito se situa, age e interage no cotidiano. Para Jodelet,

representações sociais devem ser estudadas articulando elementos afetivos, mentais e sociais, integrando ao lado da cognição, da linguagem e da comunicação, a consideração das relações sociais que afetam as representações sociais e a realidade material, social e ideal sobre as quais elas vão intervir (JODELET, 1989, p. 41).

Nessa abordagem, a compreensão é de sujeito social. As representações, por serem modos de pensar compartilhados pelos diferentes grupos, medeiam a interação dos sujeitos sociais com a realidade, com os objetos e com os fatos sociais que a compõem. Na mesma linha de pensamento, as representações sociais referem-se a alguma coisa e são construídas por alguém, ou seja, existe a ligação direta entre sujeito e objeto na qual a simbolização e a interpretação lhe conferem significado. Portanto, ao mesmo tempo, temos construção e atitude do sujeito, articulação que integra o sujeito epistêmico ao sujeito psicológico. Então, conhecer a representação social da formação dos professores da rede estadual pode ampliar o espaço de discussão acerca da formação inicial desse profissional.

Decorrente desta compreensão julgamos como relevante a contribuição da Teoria das Representações Sociais para esta investigação, uma vez que ela pode permitir a identificação dos sentidos atribuídos à formação do professor e, ao mesmo tempo, apontar constitutivos da representação correlacionados ao espaço ocupado pelo professor e, ainda, com igual intensidade, proporcionar reflexões para as políticas educacionais norteadoras dessa formação.

Segundo Madeira (2000), o sentido de uma representação social não pode ser captado se o isolamos da dinâmica em que se vai configurando, cristalizando-o. Tal sentido não se esgota na linearidade do dado, mas vai delineando-se nas imbricações, contradições e conflitos impostos pela vivência do real. Essa dialética faz da representação social enunciadora do sentido existente e, ao mesmo tempo, prenunciadora do espaço possível de sua transformação. 
Assim, considerando que, segundo Dotta (2006), as representações sociais dos professores são construídas com base na apropriação da prática, das suas relações e dos saberes históricos e sociais, estudá-las possibilita a organização e a ampliação dos conhecimentos educacionais, em especial quanto à construção da identidade deles, produzindo subsídios para entender as suas necessidades profissionais, especialmente no que se refere à formação inicial.

Sendo a representação determinante na construção da identidade e influenciável pela forma de o conhecimento ser distribuído em dada realidade, é importante, para compreendê-la, a análise do contexto onde foi gerada. No caso aqui proposto, o processo de formação inicial dos professores que lecionam na rede pública estadual de Pernambuco.

\section{A Teoria das Representações Sociais}

Neste tópico, apresentamos breve análise sobre a Teoria das Representações Sociais inaugurada por Moscovici em 1961, por compreendermos que ela constitui um recurso teórico-metodológico fortemente recomendável para tratarmos do objeto em estudo. Segundo Dotta (2006, p. 41), a "Teoria das Representações Sociais constitui-se em um referencial teórico-metodológico, por tratar-se de uma teoria que traz em seu bojo um método".

A palavra representação, que encerra inúmeros significados, é um termo clássico da Filosofia e da Psicologia. No entanto, foi a partir do trabalho de Moscovici (1978), "A Representação Social da Psicanálise", que tal termo passou a ser usado com mais destaque. Esse trabalho visava a explicar como formas de conhecimento geradas por determinado grupo social são apropriadas, reconstruídas por outros grupos; introduziu, assim, a noção de representações sociais.

Em seu trabalho, Moscovici coloca em cena o conhecimento do senso comum, que, até então, era considerado de menor importância em relação ao elaborado dentro dos padrões da ciência. Em decorrência desse 
fato, buscou demonstrar a permanente relação entre o que a ciência produz e o retorno para o contexto social - quando os sujeitos se apropriam, recriam e utilizam os conhecimentos oriundos da ciência no seu cotidiano e concebeu a representação social como instrumento que valoriza o conhecimento e as experiências do senso comum.

Moscovici, ao trazer o saber e o fazer do senso comum para o centro da arena, evidencia que tal tipo de conhecimento também faz história, muda rumos, constrói cultura, amplia horizontes, sustenta e fornece as condições materiais, até mesmo para os grupos privilegiados se apropriarem da ciência. Nesse sentido, a representação social não se embasa em concepção individualista, ao contrário, aponta para a construção social dos sujeitos em determinada sociedade, isto é, os indivíduos pensam, agem, elaboram conceitos, definições, realizam práticas sociais coletivamente.

Atualmente, o estudo da mencionada teoria está em plena expansão no Brasil: ampliam-se as áreas que têm aderido a esse referencial, incluindo educação, saúde e serviço social, bem como crescem os trabalhos de pesquisa. Pode-se afirmar que tal crescimento se deve ao fato de que os estudos em representações sociais vêm mostrando o quanto essa noção e sua correlata base teórica permitem compreensão e explicação aprofundadas dos fenômenos sociais.

As representações sociais não se baseiam em concepção individualista, mas apontam para a construção social dos sujeitos em determinada sociedade, isto é, indivíduos que pensam, agem, elaboram conceitos, definições, realizam práticas sociais coletivas. Não se trata de simples mecanismos, de cópias de impressões individuais, mas de resultado da interação homem e sociedade, em constante reinvenção de situações, conflitos e propostas. De fato, o meio social é que faz a mediação entre o ser e o objeto.

De acordo com Moscovici (1978), a definição de representações sociais, uma forma de conhecimento social, assenta-se, portanto, em três aspectos importantes: a comunicação, a reconstrução do real e o domínio do mundo. Comunicação, porque as representações oferecem às pessoas um código para suas trocas e para nomear e classificar as partes de seu mundo, de sua história. Reconstrução do real, porque é na constante 
dinâmica comunicação-representação que os sujeitos reconstroem a realidade cotidiana. As representações sociais atuam como guias de interpretação e de organização da realidade, fornecendo os elementos a fim de os sujeitos se posicionarem diante dela e definirem a natureza das próprias ações sobre ela. As representações participam da construção do real, a qual só existe enquanto tal nas interações dos indivíduos ou grupos com os objetos sociais.

Segundo Sá (1996), a aludida teoria desdobra-se em três correntes teóricas complementares: uma é mais fiel à teoria original e tem como representante Jodelet, em Paris; outra procura articular a anterior com a perspectiva mais sociológica e é liderada por Doise, em Genebra; e, por fim, a terceira abordagem, enfatiza a dimensão cognitivo-estrutural das representações, e é liderada por Abric, em Aix-en-Provence.

Este estudo utiliza como aporte teórico a Teoria das Representações Sociais bem como a abordagem estrutural representada principalmente por Abric (1994).

\section{Perspectiva metodológica}

A Teoria das Representações Sociais, desenvolvida por Moscovici, se apresenta como um recurso teórico fortemente recomendável para o tratamento desse objeto por possibilitar uma abordagem multidisciplinar e multifacetada de um fenômeno que se situa no encruzamento de aspectos sociais e psicológicos que envolvem tanto a dimensão cognitiva quanto afetiva dos sujeitos.

Por ser uma teoria ampla não é recomendado um único procedimento metodológico para abranger todas as informações que envolva um objeto de Representações Sociais, podendo então, serem utilizados vários métodos de pesquisa para caracterizar primeiro o tipo de objeto a ser pesquisado, e posteriormente selecionar métodos coerentes visando a melhor maneira de levantar e analisar os dados. 
Nesse estudo, utilizamos dois instrumentos de coleta dados: o questionário de associação livre (ABRIC, 1994) e o de associação dirigida (SILVA, 2008).

Primeiro utilizamos o questionário de associação livre, composto por duas partes. Na primeira continha perguntas que possibilitaram a construção do perfil dos sujeitos, e a segunda com a expressão indutora. Essa técnica tem o objetivo de identificar o campo semântico das representações, de modo a podermos identificar os elementos latentes. Para isso, é solicitado ao sujeito a produção de palavras a partir de um termo indutor, frases ou expressões que lhe vierem à mente. Eis o caráter diferencial dessa técnica, ela dá ao sujeito um caráter espontâneo, mais indutivo, permitindo com isto acessar de forma eficiente os elementos componentes do campo semântico sobre o objeto estudado. No estudo proposto o termo indutor foi a expressão "Formação".

Segundo Abric (1994), um procedimento metodológico que permite reduzir a parte de interpretação ou da elaboração da significação do próprio pesquisador é solicitar ao sujeito que, a partir da própria produção, analise e compare os dados obtidos numa primeira etapa do estudo - no nosso caso, a associação livre. Esse procedimento torna, portanto, a análise dos resultados mais pertinente.

Sendo assim, com base nas associações produzidas nos questionários de associação livre, obtivemos o primeiro recorte das palavras necessárias para a realização da associação dirigida. Essa técnica consiste em pedir ao sujeito, mediante um conjunto de palavras produzidas por ele mesmo na associação livre, que selecione aquelas que mais se aproximem do objeto em estudo, sem determinar a quantidade de palavras que devem ser associadas. Quando uma palavra é escolhida diversas vezes, isso possibilita o levantamento dos termos associados aos elementos da representação que podem ser seus organizadores (ABRIC, 1994).

A grande quantidade de ligações, ou conexões, que dado elemento mantém com outros da representação, frequentemente, tem sido tomada como indicativo de sua provável participação no núcleo central. O levantamento dessas ligações constitui instrumento importante nos estudos de 
representações sociais, assim como contribui para a produção empírica sistemática para o desenvolvimento da teoria do núcleo central (MOLINER, 1994).

Participaram da amostra 80 professores, 50 dos anos finais do ensino fundamental e 30 do ensino médio, de 20 escolas da rede pública estadual de Pernambuco. Na nossa primeira observação referente à variável "sexo" evidenciamos a predominância do sexo feminino (65\%) contra $35 \%$ do sexo masculino. $\mathrm{Na}$ análise qualitativa, constatamos que no ensino médio têm maior número de docentes homens e, nas disciplinas de ciências humanas a predominância é de mulheres. Quanto à relação idade e tempo de serviço, a amostra retrata maior número de professores com experiência, mais de 10 anos de atuação na Educação Básica. Em relação à faixa etária, quase metade dos docentes (43\%) encontram-se na faixa etária de 35 a 50 anos; apenas $8 \%$ entre 25 e 34 anos.

\section{Resultados}

Obtivemos como resultados do questionário de associação livre, 400 palavras que foram associadas à palavra estímulo (Formação) das quais 38 diferentes; as mais evocadas tiveram frequência igual ou superior a 3 .

Tabela 1 - Palavras associadas ao termo formação $(n=38)$

\begin{tabular}{lllclc}
\hline $\begin{array}{l}\text { Palavras } \\
\text { Associadas }\end{array}$ & F & $\begin{array}{l}\text { Palavras } \\
\text { Associadas }\end{array}$ & F & $\begin{array}{l}\text { Palavras } \\
\text { Associadas }\end{array}$ & F \\
\hline Didática & 32 & Metodologia & 10 & Aperfeiçoamento & 5 \\
Disciplina & 28 & Conteúdo & 10 & Atualização & 5 \\
\hline Conhecimento & 26 & Profissão & 10 & Compromisso & 5 \\
Licenciatura & 22 & Competência & 9 & Informação & 5 \\
\hline Estudo & 20 & Cultura & 8 & Capacitação & 5 \\
\hline Aprendizagem & 20 & Saber & 8 & Desafio & 5 \\
\hline Ensino & 17 & Experiência & 8 & Ética & 5 \\
\hline Educação & 17 & Currículo & 7 & Desenvolvimento & 3 \\
\hline
\end{tabular}

(Continua) 
Tabela 1 - Palavras associadas ao termo formação $(n=38)$

\begin{tabular}{llllll}
\hline Palavras & F & $\begin{array}{l}\text { Palavras } \\
\text { Associadas }\end{array}$ & F & $\begin{array}{l}\text { Palavras } \\
\text { Associadas }\end{array}$ & F \\
\hline Planejamento & 16 & Identidade & 7 & Futuro & 3 \\
Prática & 16 & Faculdade & 7 & Universidade & 3 \\
\hline Cidadania & 12 & Responsabilidade & 7 & Realização & 3 \\
Trabalho & 12 & Desempenho & 6 & Sucesso & 2 \\
\hline Teoria & 10 & Reflexão & 6 & & \\
\hline
\end{tabular}

Fonte: Dados organizados pelas autoras, com base nos resultados dos questionários de associação livre.

A fim de aprofundar a análise dos dados, elaboramos, com base nas palavras associadas, categorias que nos permitiriam delinear, de modo mais detalhado, o campo semântico das representações sociais dos professores sobre a formação.

De início, selecionamos as palavras que nos pareceram mais representativas; depois, elaboramos as categorias de acordo com a natureza dos conteúdos apreendidos. Assim, obtivemos conteúdos relacionados às dimensões acadêmica, pedagógica e profissional.

$\mathrm{Na}$ categoria acadêmica, vêem-se as palavras que fazem parte do processo de formação inicial do professor e para o desenvolvimento intelectual, tais como (licenciatura, estudo, conhecimento, teoria, informação, cultura, saber, currículo, faculdade). Na categoria pedagógica verificam-se palavras que expressam aspectos referentes ao processo de desenvolvimento da prática pedagógica, entre outras temos (didática, disciplina, ensino, aprendizagem, metodologia, conteúdo, prática, educação). E por fim, na categoria profissional, palavras que expressam o entendimento sobre a identidade profissional, a qual, de acordo com Pimenta (2000), se constrói com base na significação social da profissão, (trabalho, profissão, capacitação, experiência, futuro, ética).

As representações dos professores mostram um percentual elevado da dimensão pedagógica (44\%) e da dimensão acadêmica (33\%). A categoria da dimensão profissional aparece apenas com $23 \%$. 
Nesse sentido, nota-se na análise das representações, que os professores elegem como conhecimentos importantes para a formação tanto os conteúdos específicos da área a ser ensinada quanto a forma de eles serem ensinados.

Assim, de acordo com os dados apresentados, o elemento fundamental do ensino nessa perspectiva é a lógica organizacional do conteúdo a ser ensinado, suas partes e pré-requisitos sem maiores preocupações com os sujeitos da aprendizagem e com o contexto em que ela deveria acontecer. Esses resultados permite-nos afirmar que o sentido dado à docência pelos professores pesquisados fundamentou-se na racionalidade técnica instrumental tal como definida por Schön (1992).

Segundo esse autor, a racionalidade instrumental no trabalho pedagógico caracteriza-se como uma perspectiva racional que atribui a eficiência do trabalho pedagógico à seleção e à adoção de técnicas com base no conhecimento produzido sob os auspícios da ciência de inspiração positivista, mediante aplicação de instrumentos para a consecução de fins previamente definidos (SCHÖN, 1992).

Embora se compreenda a importância desses conhecimentos de natureza eminentemente técnica, argumentamos, com base no que se discute na atualidade (Schön,1992, Zeichner,1993; Pimenta, 2000; entre outros) que eles não abarcam a amplitude dos saberes necessários para a atuação profissional de um professor. Compreendemos que na formação se contemplem os saberes disciplinares e curriculares; mas que também ofereça ao docente subsídios para ele tornar-se capaz de compreender o contexto social contemporâneo e seu papel nessa realidade, assim como habilitar-se à prática pedagógica crítica e reflexiva.

Um dado preocupante é o fato de a categoria profissional ter apresentado contribuição insignificante no campo das representações dos sujeitos e não se fazer presente nos elementos constituintes da estrutura interna dessas representações.

Esse resultado indica que as representações sociais dos professores investigados não evidenciaram relação com a construção da identidade do professor. Segundo Pimenta (2000, p. 19), "Uma identidade profissional 
se constrói, pois, a partir de significação social da profissão; da revisão constante dos significados sociais da profissão; da revisão das tradições".

A análise apresentada referente ao campo semântico das representações segue os dados da organização da estrutura interna dessas representações. Os dados produzidos por meio do questionário de associação dirigida possibilitaram-nos identificar e analisar a organização da estrutura interna das representações descritas pelos sujeitos. Isso permitiu o acesso ao núcleo central da representação sobre a formação do professor, com base na observação da frequência das palavras mais associadas pelos sujeitos e pelo levantamento das palavras consideradas as mais importantes. Segundo Moliner (1994, p. 208)

[...] em todo estudo de representação, constata-se que certas cognições, designadas por seu rótulo verbal, aparecem mais frequentemente do que outras no discurso dos sujeitos. Esse fenômeno de saliência, que aparece geralmente associado ao status central de certas cognições, não deve surpreender. Precisamente, a saliência é uma consequência do valor simbólico das cognições centrais.

Destaca o referido autor que para a detecção dos elementos constituintes do núcleo central é necessário, além da saliência, a verificação do poder associativo desses elementos. Observando essa orientação, seguem as palavras elencadas na associação dirigida nas respectivas categorias.

Tabela 2 - Palavras associadas à expressão "Formação" ( $n=12)$

\begin{tabular}{lclcll}
\hline Palavras Associadas & F & Palavras Associadas & F & Palavras Associadas & F \\
\hline Conhecimento & 42 & Ensino & 15 & Disciplina & 9 \\
Aprendizagem & 23 & Desenvolvimento & 10 & Profissão & 7 \\
\hline Estudo & 22 & Didática & 10 & Trabalho & 5 \\
Licenciatura & 20 & Responsabilidade & 9 & Compromisso & 5 \\
\hline
\end{tabular}

Categorias: pedagógica, acadêmica, profissional

Fonte: Dados organizados pelas autoras, com base nos resultados dos questionários de associação dirigida. 
Observa-se no campo semântico das representações dos professores, percentual elevado da dimensão pedagógica (44\%) e da dimensão acadêmica (33\%). No entanto na estrutura interna observa-se que a dimensão acadêmica passa a predominar com 53\%, a pedagógica com $33 \%$ e a profissional com $14 \%$, ou seja, com percentual inferior ao campo semântico.

Considerando que as representações da formação são ancoradas na categoria acadêmica, é possível atribuir uma forte influência desse processo vinculado à formação inicial, oferecidas nos cursos de licenciatura. Com base nessa constatação, salientamos a importância dos cursos de formação de professores oferecerem aos alunos a oportunidade de aprenderem os diferentes saberes, a fim de poderem exercer sua tarefa da melhor maneira possível, pois "ensinar supõe aprender a ensinar, ou seja, aprender a dominar progressivamente os saberes necessários à realização do trabalho docente" (TARDIF, 2002, p. 20).

Convém, ainda destacar que ninguém se torna professor do dia para a noite, o processo é longo e complexo: começa nas vivências do curso de formação inicial e passa pelas diversas experiências construídas a partir do conhecimento dos diferentes saberes - disciplinares, curriculares, da tradição pedagógica, experienciais -, o que se traduz na prática pedagógica, característica da profissão docente.

Quanto à questão da dimensão profissional, outro desafio para os cursos de formação inicial é colaborar no processo de passagem de o aluno enxergar-se como professor, isto é, ajudá-lo a construir a sua identidade de professor. Nesse sentido, é fundamental que nos cursos de formação de professores, a dimensão profissional também seja contemplada. No entanto, nossos dados apontam que a categoria profissional como aquela que menos aparece nos campos semânticos das representações sociais em estudo.

Diante de tais resultados, podemos inferir que as representações do referido grupo de professores estão ancoradas na premissa básica de que, para formar o docente é necessário ensinar um corpo de conhecimentos estabelecidos e legitimados pela ciência e pela cultura, especialmente 
pelo valor intrínseco que representam. Visto por esse ângulo, o aspecto mais importante do ensino volta-se para a seleção e organização do conteúdo a ser ensinado, realçando-se seus elementos, suas partes e pré-requisitos. Sendo assim, o conhecimento, tido como puro reflexo dos objetos, se organiza sem a mediação dos sujeitos.

Na mesma direção, as características do trabalho do professor também são tributárias dessa lógica organizacional e da neutralidade: segurança, transmissão caracterizada pela metodologia da demonstração, parâmetros únicos de avaliação.

Vale ressaltar que não é objetivo das representações sociais pesquisar uma forma homogênea de agir do grupo, pois identificar a Representação Social de algum objeto em determinado grupo não significa dizer que todos daquele grupo agirão com a mesma conduta ou formularão os mesmos pensamentos, pois os indivíduos trazem consigo experiências particulares da vida e inserções específicas na sociedade.

\section{Considerações finais}

Compreendendo o conhecimento como processo dinâmico e que todo produto final da análise de uma pesquisa assume caráter de incompletude, não pretendemos elaborar conclusões definitivas ou generalizações, mas, aproximações que subsidiem as discussões sobre a formação do professor. É nesse sentido que apresentamos algumas considerações a respeito das análises por nós realizadas ao longo deste estudo.

A análise da representação social da formação dos professores da rede estadual nos permitiu compreender o que subjaz a tal processo formativo e identificar os significados atribuídos pelos sujeitos e as dimensões integrantes do mencionado processo.

Os resultados revelaram que as representações sobre a formação circulam em torno das categorias pedagógica, acadêmica e profissional, predominando a categoria da dimensão pedagógica. No entanto, observa-se que as representações da formação são ancoradas na categoria 
acadêmica, ou seja, uma forte influência desse processo vinculado à formação inicial, oferecidas nos cursos de licenciatura. A categoria profissional apresentou contribuição insignificante tanto no campo semântico como na estrutura interna das representações dos sujeitos investigados.

Nossos dados apontam, tanto no campo semântico quanto na organização da estrutura das Representações Sociais, que apesar da emergência do movimento internacional de ruptura com o paradigma da racionalidade técnica instrumental (SCHÖN, 1992), as representações dos docentes ainda se fundamentam na concepção de formação que foi construída historicamente, ou seja, na compreensão de que a formação encontra-se circunscrita à aquisição dos conhecimentos específicos da área e à forma de como ensiná-los.

Segundo Thompson (1992), o surgimento de novas orientações curriculares, a participação em ações de formação ou a leitura de textos a respeito das teorias educacionais podem suscitar boas perspectivas em relação à prática pedagógica. No entanto, a tendência que observamos nos professores é acomodar os novos elementos às estruturas conceituais preexistentes, modificando-os tanto quanto necessário de modo a deixar aquelas estruturas basicamente inalteradas. Isso também esteve presente na nossa pesquisa: diversos sujeitos, em ocasiões distintas, reivindicavam formação centrada nos aspectos pedagógicos, quando evocavam palavras mais associadas a esse aspecto. Com base em tais constatações, inferimos que as representações sobre a formação docente ainda está muito imbricada no modelo da "racionalidade técnica" (SCHÖN, 1992).

De outra parte, entendemos que a superação de uma concepção em favor de outra e a instauração de mudanças não constituem processo rápido nem simples; ao contrário, demanda compreensão e amadurecimento das novas ideias, desapego aos antigos modelos e práticas, consciência da necessidade de mudar e disposição para a mudança.

A propósito, Ponte (1992), em estudo realizado sobre processos de mudança nas concepções de professores, observou que após um período de formação em programa de atualização com professores de Matemática, ocorreram mudanças importantes em relação à utilização de 
novas metodologias. No entanto, nos aspectos mais centrais - quanto à forma de eles encararem e de estarem na profissão - , não houve mudanças significativas.

Ainda segundo Ponte (1992), as dificuldades dos professores com a reflexão podem estar relacionadas aos aspectos profundos da sua cultura: concepções profundamente enraizadas sobre o que é ser professor. Para o mesmo autor, tais aspectos são muito mais difíceis de mudar do que a mera adoção de nova orientação pedagógica.

A mudança de concepções e de práticas constitui um processo difícil e penoso em relação ao qual as pessoas oferecem resistência natural e, de certo modo, saudável (BENAVENTE, 1990). É difícil mudar as pessoas, especialmente quando não estão empenhadas em efetuar tal mudança.

Essas dificuldades também se mostraram nos nossos dados. Mesmo evidenciada, no campo semântico, representação com um percentual significativo da dimensão pedagógica, os docentes pesquisados revelaram como constituintes do núcleo central da representação social da formação os elementos da categoria acadêmica.

Nessa perspectiva, constitui-se um desafio para os cursos de formação de professores, organizar os seus currículos de modo a permitir aos futuros docentes vivenciar experiências de aprendizagem desejáveis para seus futuros alunos, de modo intelectualmente provocador, instigante, problematizador.

Importa aos futuros professores desenvolver atitude de abertura em relação à experimentação e à inovação. Tornar-se realmente profissionais à medida que ensinam e refletem sobre o seu ensino. Logo, o principal objetivo da formação volta-se para o fim de possibilitar ao formando a preparação e o envolvimento no próprio desenvolvimento profissional. Importa destacar a necessidade de se considerar o conhecimento educacional, que inclui contribuições das ciências da Educação e possibilita a tomada de consciência dos problemas educacionais e a reflexão sobre eles.

A análise da representação social da formação dos professores da rede estadual nos permitiu compreender o que subjaz a tal processo 
formativo e identificar os significados atribuídos pelos sujeitos e as dimensões integrantes do mencionado processo.

Esperamos que esta investigação contribua para a melhoria do processo de formação profissional do professor e, sobretudo, que possibilite as instituições formadoras refletirem sobre suas práticas docentes e pedagógicas.

\section{Referências}

ABRIC, J. C. Pratiques sociales et représentations. Paris: PUF, 1994.

ALLOUFA, J. M. L.; MADEIRA, C. M. Representação social e educação: que relação é essa? II Colóquio Franco Brasileiro Educação e Linguagem. GT Educação e Representação Social, 1990.

ALVES, N. Trajetórias e redes na formação de professores. Rio de Janeiro: DP\&A, 1998.

BENAVENTE, A. O computador e a mudança na escola. In: BERNARDES, A.; VELOSO, E. (eds) Actas do Encontro "o computador na sala de aula". Lisboa: Projeto Minerva, 1990.

BRZEZINSKI, I. Pedagogia, pedagogos e formação de professores - Busca e Movimento. Campinas: Papirus Editora, 1996.

CUNHA, M. I. O bom professor e a sua prática. Campinas, SP: Papirus, 1994.

DOTTA, L. T. T. Representações Sociais do ser professor. Campinas, SP: Editora Alínea, 2006.

FERREIRA, A. C. Um olhar retrospectivo sobre a pesquisa brasileira em formação de professores de matemática. In: FIORENTINI, D (org.). Formação de professores de Matemática. Campinas, SP: Mercado de Letras, 2003.

GATTI, B. A construção da pesquisa em Educação no Brasil. Brasília, DF: Plano, 1997. 
GAUTHIER, C. Por uma teoria da Pedagogia: pesquisas contemporâneas sobre o saber docente. Ijuí: Unijuí, 1998.

JODELET, D. Lés representations sociales. Paris: PUF, 1989.

LIBÂNEO, J. C. Adeus Professor, Adeus Professores? Novas exigências educacionais e profissão docente. São Paulo: Cortez, 1998.

MADEIRA, M. C. Um aprender do viver: educação e representação social. In: MOREIRA, A. S. P.; OLIVEIRA, D. C. (Org.). Estudos interdisciplinares de representação social. 2. ed. Goiânia: AB, 2000.

MAZZOTI, A. J. Representações sociais: desenvolvimentos atuais e aplicações à educação. In: Linguagens, espaços e tempos no ensinar e aprender / ENDIPE - Rio de Janeiro: DP\&A, 2000.

MOLINER, P. Les méthodes de réperage et d'identification du noyau dês représentations sociales. In: C. GUIMELLI (Ed). Structures et transformations dês représentations sociales. Neuchâtel: Delachaux et Niestlé, 1994.

MOSCOVICI, S. A Representação Social da Psicanálise. Rio de Janeiro: Zahar, 1978.

PIMENTA, S. G. (org.). Saberes pedagógicos e atividade docente. São Paulo: Cortez, 2000.

PONTE, J. P. Concepções dos professores de Matemática e processos de formação em Educação Matemática. Portugal. Seção de Educação Matemática da Sociedade de Ciências da Educação de Lisboa. p. 187-239, 1992.

SÁ, C. P. de. Núcleo central das Representações Sociais. Petrópolis: Vozes, 1996.

SCHÖN, D. Formar professores como profissionais reflexivos. In: NÓVOA, A. (coord.) Os professores e sua formação. Lisboa: Dom Quixote, 1992.

SCHULMAN, L. S. Those who understand: knowledge growth in teaching. Educational Researcher, v. 15, n. 2, p. 4-14, 1986. 
SILVA, R. D. da. A formação do professor de Matemática: um estudo das Representações Sociais. 2008. F 240 f. Tese (Doutorado em Educação). Universidade Federal de Pernambuco. Recife, 2008.

TARDIF, M. Saberes profissionais dos professores e conhecimentos universitários. Revista Brasileira de Educação. ANPED, n. 13, 2000, p. 5-23.

TARDIF, M. Saberes docentes e formação profissional. Petrópolis: Vozes, 2002.

THOMPSON, A. G. Teachers beliefs and conceptions: A synthesis of the research. In: D. A. Grouws (Ed) Handbook of research in mathematics teaching and leaning. New York, NY: Macmillan, 1992.

ZEICHNER, K. M. A formação reflexiva dos professores: idéias e práticas. Lisboa: Educa, 1993.

Recebido: 16/12/2015

Received: 12/16/2015

Aprovado: 20/05/2016

Approved: 05/20/2016 
